\title{
Quantitative Real-Time PCR as a Novel Detection Method for Micro-RNAs Expressed by Cervical Cancer Tissue: A Review
}

\section{Rashmi Nathasha Wickramasinghe ${ }^{1}$, Nakandala Darshana Suraj Goonawardhana ${ }^{2}$, Samanthi Priyanganee Premaratne ${ }^{3}$, Poruthotage Pradeep Rasika Perera1}

${ }^{1}$ Faculty of Medical Sciences, Department of Biochemistry, University of Sri Jayewardenepura, Nugegoda, Sri Lanka ${ }^{2}$ Synergy-Bio Pvt. Ltd., Malabe, Sri Lanka

${ }^{3}$ Apeksha Hospital, Maharagama, Sri Lanka

Email: r.nathasha.w@gmail.com

How to cite this paper: Wickramasinghe, R.N., Goonawardhana, N.D.S., Premaratne, S.P. and Perera, P.P.R. (2021) Quantitative Real-Time PCR as a Novel Detection Method for Micro-RNAs Expressed by Cervical Cancer Tissue: A Review. Journal of Biosciences and Medicines, 9, 100-115.

https://doi.org/10.4236/jbm.2021.99009

Received: August 9, 2021

Accepted: September 10, 2021

Published: September 13, 2021

Copyright $\odot 2021$ by author(s) and Scientific Research Publishing Inc. This work is licensed under the Creative Commons Attribution International License (CC BY 4.0).

http://creativecommons.org/licenses/by/4.0/

(c) (i) Open Access

\begin{abstract}
The potential of microRNAs (miRNA) as biomarkers of Cervical Cancer (CC) is analyzed extensively by many researchers today. However, some studies have shown that miRNAs are expressed in cancers and may act as a better diagnostic strategy than the Pap smear or even assist it as a screening strategy. MicroRNA expression has been shown to differ in precancerous lesions as well as in cervical cancer tumours from that of normal tissue. With the use of quantitative real-time PCR (qRT-PCR), microRNAs can be detected in many sample types ranging from biopsy samples to blood (serum and plasma). Early detection of the disease is possible due to the aberrant expression of miRNAs in precancerous stages as well as advanced stages of the disease; this proves that they have the potential to be an ideal novel biomarker for CC. This review discusses studies using qRT-PCR to detect the expression of miRNAs within the years 2008-2019 and focuses on giving an insight into the types of samples and kits that have been used. Publications which have used qRT-PCR as a primary or secondary detection method were selected via Google Scholar Search and PubMed. Studies were shown to have used a variety of kits and reagents, but all have applied the main principle of qRT-PCR. Quantitative Real-Time PCR is shown to be a versatile and accurate detection technique for miRNAs of CC.
\end{abstract}

\section{Keywords}

Real-Time PCR, Cervical Cancer, miRNA 


\section{Introduction}

Cervical cancer is the fourth most common type of cancer that affects women globally [1]. It has been reported that an estimated 570,000 new cases were recorded in 2018; this represents $6.6 \%$ of all female cancers. Epidemiological statistics show that a high mortality rate of $90 \%$ occurred in low- and middle-income countries. However, the global mortality rate can be reduced by implementing comprehensive prevention strategies, early diagnosis, as well as effective screening and treatment programs [1]. It has been shown through many studies that utilizing qRT-PCR to detect miRNA biomarker expression in precancerous lesions and CC tumours can act as a potential screening/diagnostic tool for CC.

The current prevention strategy for CC is the Papanicolaou test (pap-smear) analysis, which is an invasive technique and does not appeal to all female patients [2]. This is primarily a histopathological technique of screening and analysis that can be time-consuming and labor intensive. However, genetic markers have played an important role in tumour dynamics; they are a novel diagnostic technique and help assist the cytological (pap-smear and biopsies) diagnostic results. A possible genetic marker for CC is miRNA and it has the potential to be a novel non-invasive diagnostic criterion in detecting cervical cancer. In order to analyze the expression of these biomarkers only a few techniques could be used, out of which the most effective method would be qRT-PCR.

The study of miRNAs as a potential diagnostic tool for cervical cancer is a novel approach. Circulating miRNAs of different neoplasia reflect the pattern observed in the tumour tissues, giving rise to the possibility of using circulating miRNAs as easily detectable tumour biomarkers, and this property of miRNAs would especially be helpful for early diagnosis [3] [4] [5] [6]. Research shows that due to their small size, miRNAs are more stable compared to messenger RNAs (mRNAs), which allows for expression profiling from fixed tissues or other biological materials. This supports the possible use of miRNAs as the novel, minimally invasive, and robust biomarkers. MicroRNAs can be extracted from frozen and paraffin-embedded tissues, blood, circulating exosomes, and from biological fluids such as urine, saliva and even sputum proving their versatility as biomarkers [7]-[13]. Quantitative real-time PCR is regarded as the best detection method due to miRNAs being highly sensitive to this technique, it is used to amplify DNA/RNA, which depends on fluorescence emission to detect the amplified target gene. This technique is highly sensitive and does not require large amounts of RNA, and it can detect very low levels of miRNA. This technique relies on a variety of steps to detect target sequences, miRNA must be isolated with the appropriate kit and reagents after which it undergoes reverse transcription, and the cDNA of the selected miRNA is synthesized with sequence-specific primers making qRT-PCR very accurate and reliable.

The aim of this review is to analyze how different studies have used varying types of samples and qRT-PCR as a primary or secondary detection tool to analyze the expression levels of selected miRNAs specific to cervical cancer. 


\section{Methodology}

Journal articles were filtered according to research methodology and year of publication; studies which have used qRT-PCR as a primary or secondary detection tool for miRNA have been analysed in this review. Online databases such as Google Scholar and PubMed were referred when searching for journal articles. The following search terms: "miRNA + cervical cancer + qRT-PCR", "miRNA detection + cervical cancer + qRT-PCR", and "cervical cancer + specific miRNA + detection", were used to find the appropriate articles on PubMed in all fields. The same terms were searched on Google Scholar. Refer Figure 1 for a detailed view of the literature selection process.

\subsection{Inclusion Criteria}

- Studies using qRT-PCR as a primary or secondary detection tool;

- Studies which have exclusively evaluated the expression of miRNAs in CC samples as a potential biomarker;

- Studies where full-text was available for free;

- Studies published in English.

\subsection{Exclusion Criteria}

- Studies which have not used qRT-PCR as a detection tool regardless of evaluating miRNA expression;

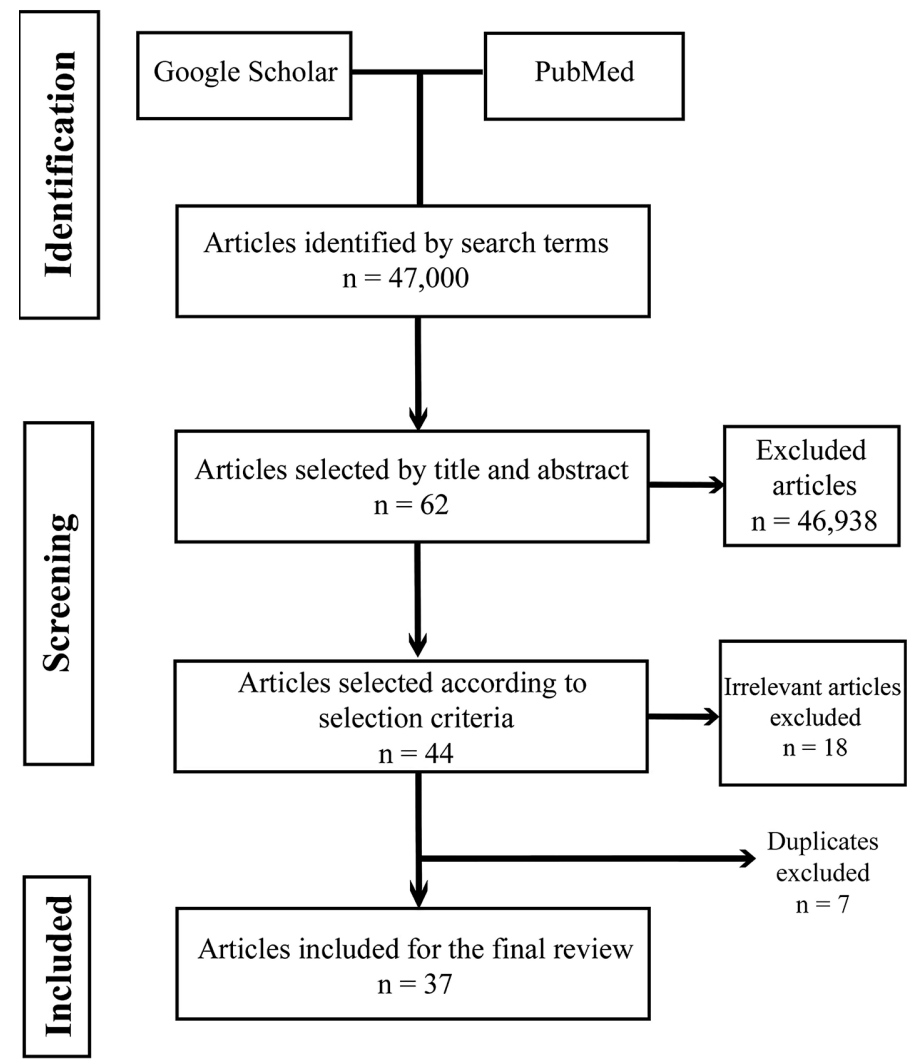

Figure 1. Flow chart demonstrating the literature selection process. 
- Studies which have only used cell lines to analyse miRNA expression;

- Studies only analysing the role of miRNA and target gene functions.

There was no discrimination against sample type and size, collection method and storage.

\section{Quantitative Real-Time PCR vs the Pap Smear}

Using qRT-PCR to detect miRNA biomarkers in CC is a novel technique and there is potential for this to be a good candidate as a new screening/diagnostic procedure. It requires less time and labor compared to the PAP smear technique - which requires clinicians to prepare a slide that will be sent to a lab to be fixed and studied under a microscope before the result is presented. This could take a matter of days or weeks depending on the country, whereas qRT-PCR is an overnight procedure needing only one person to handle and perform making it a more cost effective and versatile procedure overall.

\section{Research Evidence of Using qRT-PCR for miRNA Detection in Cervical Cancer}

There are many studies which utilized qRT-PCR as a tool to evaluate miRNA expression in CC patients. However, there are many differences between each study when it comes to the type of sample, storage, the brand of the kits and reagents, the PCR machine, etc. A thorough methodology is important to prove the validity of a study and the potential of the detection technique as a diagnostic/screening tool.

\subsection{Sample Types Used to Detect the Expression of miRNAs in CC Patients and Healthy Controls}

Most studies used tumour tissue samples along with their adjacent normal tissues as well as known cell lines. The most common sample types were Formalin Fixed Paraffin Embedded (FFPE) tissue samples and fresh cervical tissue biopsy samples. Exfoliated cells, and blood samples (serum/plasma) were amongst the more rare sample types. Homogenized tissue samples are said to be more reliable as the concentration of miRNAs are high, but it is an invasive diagnostic procedure. Studies that have used peripheral blood samples have an upper-hand as it is a minimally invasive procedure. When it comes to blood circulating miRNAs, they are found in cell-free lipid carriers (exosomes, microvesicles, and apoptotic bodies), that are released from apoptotic/necrotic cells [14] [15]. Blood circulating miRNAs are also secreted from cells bound to protein complexes like Argonautes or high-density lipoproteins which prevent the miRNAs from degradation and from reacting with RNases [14] [15]. Since miRNAs are aberrantly expressed in cancer, the levels of blood circulating miRNA may differ from that of normal levels (cut-off value) found in a healthy person [16].

A majority of the studies have obtained control samples from the healthy tissues of the patient, whilst only one study specified the size of the biopsy sample [17]. Most studies collected samples from CC patients before they underwent 
any treatment except for two studies; one study that took samples from patients previously diagnosed with Low Grade Squamous Intraepithelial Lesion (LGSIL)/ High Grade Squamous Intraepithelial Lesion (HGSIL) and had undergone treatment [17] and the other from patients that have undergone radiotherapy [18]. One other study recruited women who had a history of cancer other than CC [19].

The most common sample types were snap-frozen tissue samples (5) [20] [21] [22] [23] [24], FFPE samples (8) [25]-[33], and tissue lesion/biopsy samples (13) [17] [25] [26] [34]-[44]. Other studies used serum or plasma (7) [18] [39] [45] [46] [47], exfoliated cells (4) [48] [49] [50] [51], and tissue samples frozen in liquid nitrogen (5) [33] [50] [52] [53] [54]. Refer Table 1 for a detailed summary of all sample types and storage conditions used in the studies discussed. Some studies followed a pre-storage sample processing protocol: One study homogenised their tissue samples in TRIzol reagent and the isolated RNA was dissolved in RNase free water and stored at $-70^{\circ} \mathrm{C}$, whilst another study rinsed the tissue samples in sterile saline before storing at $-70^{\circ} \mathrm{C}$ [17] [35]. A 2012 study embedded their samples in OCT compound before storage and, a 2014 study, divided their sample set into two and used two different storage methods; one set of tissue samples were stored in RNA Later, and the other in $4 \%$ formaldehyde for 2 days before embedding in Paraffin wax blocks [25] [36].

Table 1. Summary of sample types used by the studies in this review.

\begin{tabular}{|c|c|c|c|c|}
\hline Authors & Sample type & Sample size & Normal tissue samples & $\begin{array}{c}\text { Storage } \\
\text { temperature }\end{array}$ \\
\hline Yao and Lin, 2012 [34] & Tumour/lesion tissue & 126 & $\begin{array}{l}\text { Adjacent samples collected } 1 \mathrm{~cm} \\
\text { away from tumour/lesion tissue }\end{array}$ & - \\
\hline Xie et al., 2012 [20] & Snap-frozen tissue & 30 & - & $-80^{\circ} \mathrm{C}$ \\
\hline Wang et al., 2014 [35] & Cervical biopsy & - & - & $-70^{\circ} \mathrm{C}$ \\
\hline Zhang et.al., 2013 [21] & Snap-frozen tissue & 92 & - & - \\
\hline Wen et al., 2017 [22] & Snap-Frozen tissue & 40 & Healthy controls & $-80^{\circ} \mathrm{C}$ \\
\hline Han et al., 2015 [17] & Tumour/lesion tissue & 30 & $\begin{array}{l}\text { Adjacent samples collected } 5 \mathrm{~cm} \\
\text { away from tumour/lesion tissue }\end{array}$ & $-80^{\circ} \mathrm{C}$ \\
\hline Cheung et al., 2012 [36] & $\begin{array}{c}\text { Tumour/lesion tissue } \\
\text { embedded in OCT compound }\end{array}$ & 48 & Healthy controls & $-80^{\circ} \mathrm{C}$ \\
\hline $\begin{array}{c}\text { Jiminez-Wences et al., } 2016 \\
{[37]}\end{array}$ & Biopsy samples & 49 & - & - \\
\hline Villegas-Ruiz et al., 2014 [25] & $\begin{array}{l}\text { Biopsy samples (one part in } \\
\text { RNA later the other embedded } \\
\text { in paraffin wax-FFPE) }\end{array}$ & 45 & - & $\begin{array}{l}-70^{\circ} \mathrm{C} \text { (RNA } \\
\text { later samples) }\end{array}$ \\
\hline Gozce et al., 2015 [26] & Tumour/lesion tissue-FFPE & 98 & - & n.a. \\
\hline Deftereos et al., 2011 [27] & Tumour/lesion tissue-FFPE & 104 & 23 healthy controls & n.a. \\
\hline Bumrungthai et al., 2016 [28] & $\begin{array}{c}\text { Fresh tumour/lesion } \\
\text { tissue and FFPE samples }\end{array}$ & 79 & no & - \\
\hline Shishodia et.al., 2015 [38] & $\begin{array}{l}\text { Tumour/lesion tissue } \\
\text { samples in } 1 \mathrm{X} \text { PBS }\end{array}$ & 102 & 23 healthy controls & - \\
\hline
\end{tabular}




\section{Continued}

\begin{tabular}{|c|c|c|c|c|}
\hline Zeng et al., 2015 [29] & Lesion tissues-FFPE & 103 & 13 normal tissues & - \\
\hline Zheng et al., 2015 [30] & FFPE cervical tissue samples & 140 & 15 normal tissue samples & - \\
\hline Li et al., 2011 [22] & Snap-frozen tissue samples & 125 & 20 normal & $-70^{\circ} \mathrm{C}$ \\
\hline Bierkens et al., 2012 [31] & FFPE samples & 75 & 6 frozen HPV+ normal samples & - \\
\hline Chen et al., 2013 [39] & $\begin{array}{c}\text { Tumour/lesion tissue } \\
\text { and matched serum samples }\end{array}$ & - & - & $-80^{\circ} \mathrm{C}$ \\
\hline Ma et al., 2014 [40] & $\begin{array}{c}\text { Tumour/lesion tissue } \\
\text { and matched serum samples }\end{array}$ & 60 & 6 healthy controls & $-80^{\circ} \mathrm{C}$ \\
\hline Zhang et al., 2016 [45] & Whole blood samples_-serum & 89 & 20 healthy controls & - \\
\hline Ye et al., 2019 [48] & Exfoliated cells & 177 & - & - \\
\hline Ribeiro et al., 2015 [49] & Exfoliated cells & 65 & 49 healthy controls & $\begin{array}{l}\text { Room } \\
\text { temperature }\end{array}$ \\
\hline Malta et al., 2019 [50] & Exfoliated cells & 73 & 38 normal controls & - \\
\hline Hou et al., 2014 [44] & Fresh tissue samples & 10 & 10 normal controls & - \\
\hline Huang et al., 2016 [24] & Snap-frozen tissue samples & 126 & 64 normal controls & $-80^{\circ} \mathrm{C}$ \\
\hline Ma et al., 2015 [32] & FFPE samples & 412 & 208 cervicitis cases used as controls & - \\
\hline Zhang et al., 2017 [41] & Fresh tissue samples & 105 & - & - \\
\hline Kawai et al., 2017 [51] & Exfoliated cells from cervical mucus & $\begin{array}{c}230 \text { (total number } \\
\text { including normal samples) }\end{array}$ & N/A & $-80^{\circ} \mathrm{C}$ \\
\hline Lukic et al., 2018 [33] & FFPE samples & 40 & 10 & - \\
\hline Shen et al., 2013 [52] & $\begin{array}{l}\text { Fresh tissue samples } \\
\text { frozen in liquid nitrogen }\end{array}$ & 126 & 126 (adjacent healthy samples) & - \\
\hline Luo et al., 2015 [53] & $\begin{array}{l}\text { Fresh tissue samples } \\
\text { frozen in liquid nitrogen }\end{array}$ & 88 & 88 (adjacent healthy tissues) & $-70^{\circ} \mathrm{C}$ \\
\hline Jiang et al., 2017 [46] & Serum samples & 182 & 12 & $-80^{\circ} \mathrm{C}$ \\
\hline Leitao et al., 2014 [42] & Biopsy samples stored in RNAlater & 46 & 19 & $-80^{\circ} \mathrm{C}$ \\
\hline \multirow[t]{2}{*}{ Babion et al., 2018 [43] } & $\begin{array}{l}\text { Frozen fresh cervical tissue } \\
\text { samples cervical scrape }\end{array}$ & 51 & 8 & \\
\hline & samples in ThinPrep Medium & 187 & - & $-80^{\circ} \mathrm{C}$ \\
\hline Wei et al., 2017 [18] & Plasma samples & 120 & 120 & $-80^{\circ} \mathrm{C}$ \\
\hline Zhang et al., 2019 [54] & $\begin{array}{l}\text { Fresh tissue samples } \\
\text { frozen in liquid nitrogen }\end{array}$ & 67 & 20 & - \\
\hline Xin et al., 2016 [47] & Serum samples & 126 & 60 & $-80^{\circ} \mathrm{C}$ \\
\hline
\end{tabular}

According to the literature discussed in this review samples have been collected from women of varying stages of CC. Even pre-cancerous stages were included as some of the miRNAs were shown to be expressed early on in disease progression. Most studies have opted for normal samples taken from healthy tissues of the cancer patient itself as it is an unnecessarily invasive procedure for a healthy individual. Taking adjacent healthy tissue biopsies is more reliable as it eliminates any inter-individual discrepancies [55]. Many studies have used tissue 
samples, only a minority of the studies discussed here has used blood samples to detect miRNA expression levels. Other studies that have analyzed the levels of miRNA expressed in both tissue and corresponding plasma/serum samples have shown a correlation in expression levels. Micro RNA does not easily degrade, therefore the sample type may not be an issue, however, this depends on the type of miRNA and cancer to be detected.

In one study the miRNA expression in breast cancer was detected using FFPE samples that were put through severe thawing processes, showing that this did not degrade miRNA [56]. They concluded that this makes miRNAs a reliable biomarker for cancer detection [43]. It has also been proven that the miRNA levels of serum and tissues correlated [39] [40]. When collecting samples it is important that participants have not undergone any treatments (i.e.; chemotherapy, curative surgery) as this can affect miRNA expression, however this depends on the objectives of the study.

\subsection{The Isolation of Micro RNAs and the qRT-PCR Procedure}

Running a qRT-PCR reaction requires certain reagents and kits, however, the quality may vary between manufacturers. The studies discussed here have purchased kits from a variety of manufacturers.

Most studies were shown to have used real-time PCR machines from Applied Biosystems, the machines used are as follows: 7300 Real-Time PCR System, 7500 Fast Real-Time PCR system, 7500 Real-Time PCR system, 7900 Real-Time PCR system [17] [18] [20] [21] [24] [29] [31] [41] [44] [46] [51] [52] [54]. However, two studies opted for Stratagene machines; the MX-3000p and MX-3500P, whilst the iCycler by BioRad was used by another [33] [34] [38]. A Rotor-Gene 6000 thermocycler was used by Leitao et al. [42] and the iQ5 multicolor PCR detector system by Bio-Rad was used by Ma and colleagues [32]. A 2018 study used the $\mathrm{ViiA}^{\mathrm{TM}} 7$ real-time PCR system (ThermoFisher Scientific) for qRT-PCR [43]. The study by Cheung and colleagues used two different machines, the ABI Gene Amp 9700 PCR system for reverse transcription, and the ABI 7900 PCR system for qRT-PCR. The Gene Amp 9700 may have helped increase the yield of miRNA produced during the reverse transcription process as miRNAs are found in very low concentrations in samples [36]. Another study also used two machines: reverse transcription was performed using the QuantScript RT kit by TianGen and real-time PCR was performed using the SuperReal PreMix plus also by TianGen [30].

A commonly used miRNA isolation kit was the Ambion mirVana miRNA Isolation Kit by Life Technologies (ThermoFisher Scientific). The study conducted in 2012 used the mirVana miRNA isolation kit to isolate RNA, and applied small RNA enrichment for tissue sample [20]. Deftereos et al. [27] used the Recover All Total Nucleic Acid Isolation Kit by Ambion (ThermoFisher Scientific). One study [30] removed paraffin from tissue samples using xylene and ethanol, the RNA was extracted using the miRNeasy FFPE Kit by Qiagen, and 
the RNA samples were stored at $-80^{\circ} \mathrm{C}$ till reverse transcription and qRT-PCR. A majority of the studies were shown to have used Trizol from Invitrogen (Thermofisher Scientific) as the preferred RNA isolation reagent. Refer Table 2 for a list of all the studies that have used Trizol.

Table 2. Summary of Kits and reagents used for qRT-PCR by studies discussed.

\begin{tabular}{|c|c|c|c|c|}
\hline Technique & Kit & Manufacturer & Estimated cost & Authors \\
\hline \multirow{9}{*}{ miRNA isolation } & Ambion mirVana miRNA isolation kit & $\begin{array}{l}\text { Life technologies (Ther- } \\
\text { moFisher Scientific) }\end{array}$ & USD 384.00 & $\begin{array}{l}\text { Xie et al., } 2012 \text { [20]; Hou et al., } 2014 \\
\text { [44]; Villegas-Ruiz et al., } 2014 \text { [25]; } \\
\text { Ribeiro et al., } 2015 \text { [49]; Zhang et } \\
\text { al., } 2016 \text { [45]; Shishodia et al., } 2015 \\
\text { [38]; Luo et al., } 2015 \text { [53]; Wei et al., } \\
2017 \text { [18] }\end{array}$ \\
\hline & $\begin{array}{l}\text { Recover all total nucleic acid } \\
\text { isolation kit from applied biosystems }\end{array}$ & $\begin{array}{l}\text { Ambion (ThermoFisher } \\
\text { Scientific) }\end{array}$ & USD 374.00 & Deftereos et al., 2011 [27] \\
\hline & miRNeasy FFPE kit & Qiagen & USD 474.00 & Zheng et al., 2015 [30] \\
\hline & RNeasy FFPE kit & Qiagen & USD 484.00 & Ma et al., 2015 [32] \\
\hline & Invitrogen $^{\mathrm{TM}} \mathrm{TRIzol}^{\mathrm{TM}}$ Reagent & $\begin{array}{l}\text { Invitrogen (ThermoFish- } \\
\text { er Scientific) }\end{array}$ & USD 209-374.00 & $\begin{array}{l}\text { Gozce et al.(2015) [26]; Wen et al., } \\
2017 \text { [22]; Jiminez-Wences et al., } \\
\text { (2016) [37]; Wang et al., } 2014 \text { [35]; } \\
\text { Burmrungthai et al., 2016 [28]; } \\
\text { Cheung et al., } 2012 \text { [36]; Ye et al., } \\
2019 \text { [48]; Han et al., } 2015 \text { [17]; } \\
\text { Huang et al., } 2016 \text { [24]; Zhang et al., } \\
2017 \text { [41]; Shen et al. } 2013 \text { [52]; } \\
\text { Leitao et al., } 2014 \text { [42]; Babion et al. } \\
2018 \text { [43] }\end{array}$ \\
\hline & Mirneasy mini kit & Qiagen & USD 402.00 & $\begin{array}{l}\text { Kawai et al., } 2017 \text { [51]; Xin et al., } \\
2016 \text { [47] }\end{array}$ \\
\hline & High pure miRNA isolation kit & Roche & USD 504.50 & Lukic et al., 2018 [33] \\
\hline & $\begin{array}{l}\text { Invitrogen mirVANA miRNA } \\
\text { isolation kit }\end{array}$ & ThermoFisher Scientific & USD 326.00 & Luo et al., 2015 [53] \\
\hline & Total RNA isolation kit & $\begin{array}{l}\text { Beijing Tiandz gene } \\
\text { technology }\end{array}$ & $\mathrm{N} \backslash \mathrm{A}$ & Zhang et al., 2019 [54] \\
\hline \multirow{5}{*}{$\begin{array}{c}\text { Reverse } \\
\text { Transcription }\end{array}$} & $\begin{array}{l}\text { TaqMan MicroRNA reverse } \\
\text { transcription kit }\end{array}$ & $\begin{array}{l}\text { Applied biosystems } \\
\text { (ThermoFisher Scientific) }\end{array}$ & USD 397-1014.00 & $\begin{array}{l}\text { Xie et al., } 2012 \text { [20]; Han et al. } 2015 \\
\text { [17]; Ribeiro et al., } 2015 \text { [49]; Malta } \\
\text { et al., } 2015 \text { [50]; Jiminez-Wences et } \\
\text { al., } 2016 \text { [37]; Deftereos et al., } 2011 \\
\text { [27]; Cheung et al., } 2012 \text { [36]; Wang } \\
\text { et al., } 2014 \text { [35], Kawai et al. [51], } \\
\text { Jiang et al., } 2017 \text { [46]; Babion et al., } \\
2018 \text { [43]; Wei et al., } 2017 \text { [18] }\end{array}$ \\
\hline & $\begin{array}{l}\text { High capacity cDNA reverse } \\
\text { transcription kit }\end{array}$ & $\begin{array}{l}\text { Applied biosystems } \\
\text { (ThermoFisher Scientific) }\end{array}$ & USD 353-1360.00 & Zhang et al., 2016 [45] \\
\hline & MiraMas $^{\mathrm{TM}}$ kit & Bioo scientific & $\mathrm{N} \backslash \mathrm{A}$ & Chen et al., 2013 [39] \\
\hline & M-MLV kit & Promega & USD 25-364.00 & $\begin{array}{l}\text { Zhang et al., } 2013 \text { [21]; Luo et al., } \\
2015 \text { [53] }\end{array}$ \\
\hline & PrimeScript RT reagent kit & Takara Bio & N/A & Wen et al., 2017 [22] \\
\hline
\end{tabular}




\section{Continued}

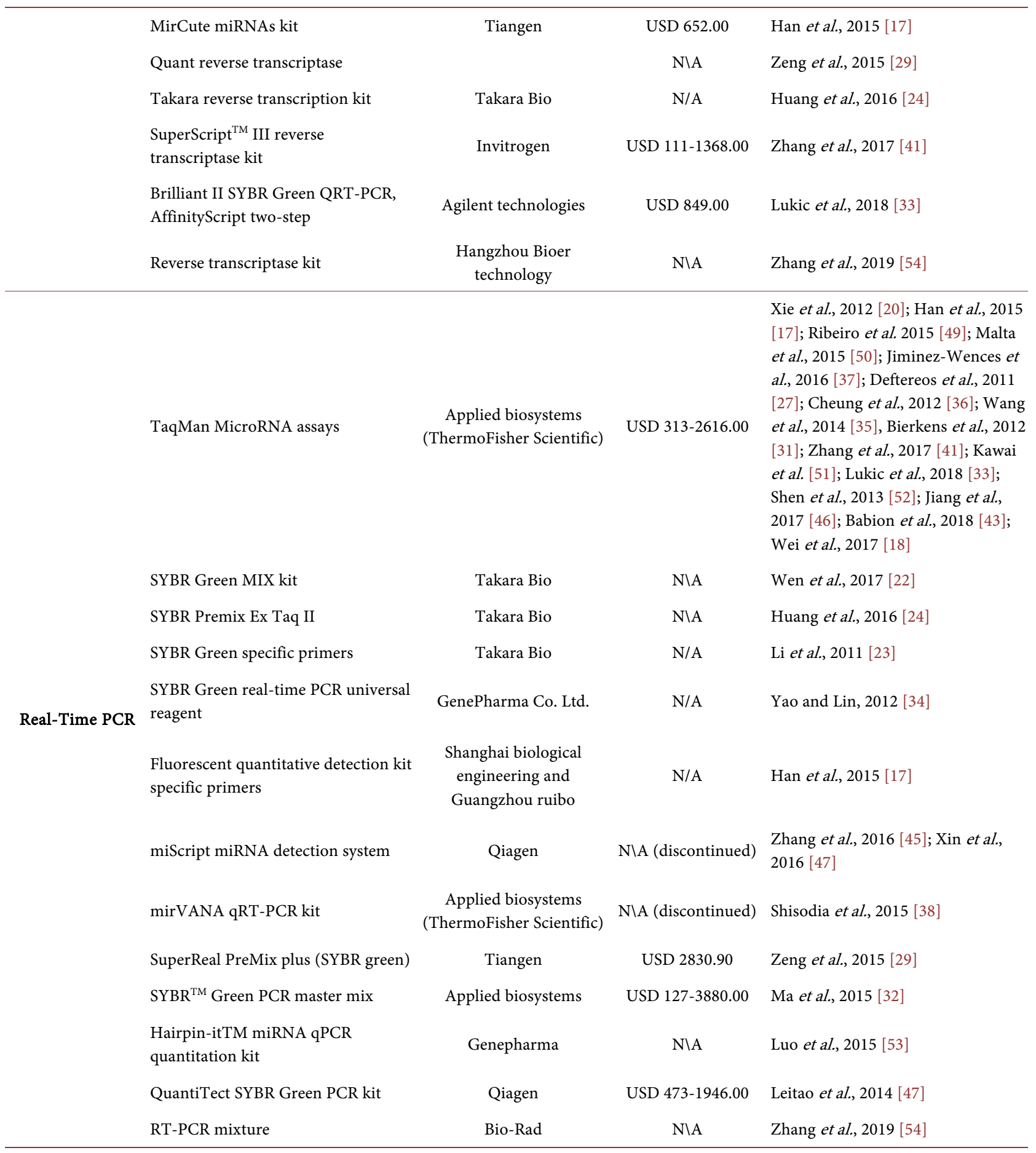

Some studies were shown to have checked RNA purity and quantity, however, they were shown to have used microarrays for miRNA detection other than qRT-PCR. Microarrays require a specific RNA concentration for detection, whereas RNA quantity may not be much of an issue for qRT-PCR as RNA is expected to be in low volumes especially miRNA as they are small in size. Han et al. [17] performed gel electrophoresis on RNA samples to check quality and only 
selected the $28 \mathrm{~S}$ bands as eligible for qRT-PCR.

Ma et al., used reverse transcription reagents from ThermoFisher, however they have not mentioned the name of the kit used, they combined these reagents with stem-loop primers from Sangon Biotech similar to Huang and colleagues who used stem-loop primers from Invitrogen [24] [32]. Studies that did not use the applied biosystems miRNA PCR assay which includes predesigned primers, opted for specific primers from Invitrogen, miScript Primer Assays (Qiagen) [24] [43]. Some studies were consistent in using the applied biosystems miRNA assay for their qRT-PCR procedure instead of opting for different kits for reverse transcription and quantitative real-time PCR [41] [43] [51] [52].

The most common RT-PCR and qRT-PCR kits used were the TaqMan Reverse Transcription kit and TaqMan MicroRNA Assays by applied biosystems. Refer Table 2 for a detailed summary of the kits and assays used by the studies discussed.

\subsection{The Effect of Different Kits on miRNA Expression}

Almost all the studies showed similar results for miRNA expression despite using different samples and processing techniques, however, most studies did use similar kits. The expression of specific miRNAs differed from one another but their level of expression remained consistent in all studies, with the exception of a few. Some studies have evaluated a panel of miRNAs instead of studying the expression levels and properties of one miRNA, this can have a better diagnostic value than detecting only one miRNA biomarker [26] [27] [29] [35] [36] [37] [38] [42] [43] [47] [49] [51].

Studies which evaluated the expression level of miRNA-196a all showed significantly high levels in diseased samples as well as cell lines compared to normal cells [21] [26] [44], except for one study which stated that there was no significant difference between miRNA-196a expression in cancer cells and healthy cells [25]. They assumed that this could be due to the heterogeneity of CC tumour cells compared to cancer cell lines [25].

\section{Discussion}

There are many things to consider in methodology design. When it comes to evaluating miRNA expression in tissue/blood samples using the qRT-PCR method many things come into play. Steps like sample processing, storage and, RNA extraction can have a significant impact on results but are easily overlooked. In miRNA profiling regardless of the type of technique, choosing the right miRNA isolation kit is of great importance and this solely depends on the sample type. The quality of the kits matter, this is why it is important to procure kits from renowned manufacturers like life technologies and applied biosystems which are part of the ThermoFisher Scientific group. Most of the studies in this review used the Ambion mirVANA miRNA isolation kit by Life Technologies, the second most common RNA isolation technique was the use of Trizol by In- 
vitrogen (ThermoFisher Scientific) which is a Chaotropic salt. Overall, products from ThermoFisher Scientific were commonly used amongst most studies discussed in this review. Sample type may also affect RNA quality, high quality miRNA can be extracted from tissues and cell lines, however, extraction from blood samples can be challenging due to endogenous RNase activity. However, it is important to note that endogenous plasma miRNA is stable in its native form therefore, extraction methods which can inactivate RNase activity rapidly are required [57]. Vigneron and colleagues [58], validated that the use of the NucleoSpin miRNA plasma/serum kit as being able to isolate more miRNA from blood samples than the widely used kits like mirNEasy kit (Qiagen) and Ambion mirVANA miRNA isolation kit (Life Technologies) agreeing with two other studies [59] [60]. The amount of miRNA extracted has a major influence on qRT-PCR results, therefore it is imperative to choose the best kit and optimize the methodology for the most reliable results. Other factors that may affect miRNA nature and quantity in blood samples are centrifugation, white blood cell count and hemolysis. It is important to note that miRNAs in plasma exist within vesicles/exosomes, or are associated with argonaute-2 (AGO2) containing protein complexes. Sample processing conditions which alter vesicle content can influence miRNA expression during evaluation [57].

The most commonly used RT-PCR and qRT-PCR kits were both from the same manufacturer, the TaqMan MicroRNA Reverse Transcription Kit and the TaqMan MicroRNA Assays by applied biosystems (ThermoFisher Scientific). The TaqMan MicroRNA Assays are shown to be the best to evaluate miRNA expression; it accommodates high-throughput platforms and is highly reproducible. The applied biosystems assay is pre-designed, making it a versatile and efficient product for miRNA detection, whereas, the mirScript kit was shown to have lower detection sensitivity [60]. Two kits have been discontinued, the mirVana qRT-PCR kit by applied biosystems is now replaced by the Applied Biosystems $^{\mathrm{TM}}$ TaqMan $^{\mathrm{TM}}$ Advanced miRNA cDNA Kit, and the miScript PCR system (Qiagen) is replaced by miRCURY LNA miRNA PCR System by Qiagen [61] [62]. The cost of the experiments depends solely on the products used, most reagents are expensive due to the advanced technologies used to make them, and another factor that may affect is shipping costs depending on the region the study is conducted in. The performance of miRNA extraction kits can be indicated via the purity and yield of extracted RNA measured using a spectrophotometer [60]. However, phenol contamination and RNA degradation can cause inconsistencies in the results, hence why direct qRT-PCR expression results are a better indicator of miRNA recovery. Sampling bias is another factor that affects RNA levels, especially when collecting blood samples. Phlebotomy process and participant's physiological state can cause changes in miRNA levels in plasma. Within healthy individuals circulating miRNAs can remain stable over time. The serum has lower levels of miRNAs leading to problems in accuracy and detection rate, hence why plasma is a better option to detect miRNA expression. 
Sample processing time and sample type can also influence miRNA levels [60].

Almost all studies agree that miRNA biomarkers detected via qRT-PCR show potential as a screening/diagnostic tool for $\mathrm{CC}$ or at most may be able to aid clinical diagnosis alongside pre-existing tests. However, more research and optimization of existing methodologies are needed to make this a possibility.

\section{Conflicts of Interest}

The authors declare no conflicts of interest regarding the publication of this paper.

\section{References}

[1] WHO (2020) Cervical Cancer. https://www.who.int/health-topics/cervical-cancer\#tab=tab 1

[2] Bray, F., Carstensen, B., Møller, H., Zappa, M., Žakelj, M.P., Lawrence, G., Hakama, M. and Weiderpass, E. (2005) Incidence Trends of Adenocarcinoma of the Cervix in 13 European Countries. Cancer Epidemiology and Prevention Biomarkers, 14, 2191-2199. https://doi.org/10.1158/1055-9965.EPI-05-0231

[3] Lawrie, C.H., Gal, S., Dunlop, H.M., Pushkaran, B., Liggins, A.P., Pulford, K., Banham, A.H., Pezzella, F., Boultwood, J. and Wainscoat, J.S. (2008) Detection of Elevated Levels of Tumour-Associated microRNAs in Serum of Patients with Diffuse Large B-Cell Lymphoma. British Journal of Haematology, 141, 672-675. https://doi.org/10.1111/j.1365-2141.2008.07077.x

[4] Heneghan, H.M., Miller, N., Lowery, A.J., Sweeney, K.J., Newell, J. and Kerin, M.J. (2010) Circulating microRNAs as Novel Minimally Invasive Biomarkers for Breast Cancer. Annals of Surgery, 251, 499-505. https://doi.org/10.1097/SLA.0b013e3181cc939f

[5] Huang, Z., Huang, D., Ni, S., Peng, Z., Sheng, W. and Du, X. (2010) Plasma microRNAs Are Promising Novel Biomarkers for Early Detection of Colorectal Cancer. International Journal of Cancer, 127, 118-126. https://doi.org/10.1002/ijc.25007

[6] Xing, L., Todd, N.W., Yu, L., Fang, H. and Jiang, F. (2010) Early Detection of Squamous Cell Lung Cancer in Sputum by a Panel of microRNA Markers. Modern Pathology, 23, 1157-1164. https://doi.org/10.1038/modpathol.2010.111

[7] Mitchell, P.S., Parkin, R.K., Kroh, E.M., Fritz, B.R., Wyman, S.K., Pogosova-Agadjanyan, E.L., Peterson, A., Noteboom, J., O’Briant, K.C. and Allen, A. (2008) Circulating microRNAs as Stable Blood-Based Markers for Cancer Detection. Proceedings of the National Academy of Sciences, 105, 10513-10518. https://doi.org/10.1073/pnas.0804549105

[8] Schwarzenbach, H., Hoon, D.S. and Pantel, K. (2011) Cell-Free Nucleic Acids as Biomarkers in Cancer Patients. Nature Reviews Cancer, 11, 426-437.

https://doi.org/10.1038/nrc3066

[9] Hanke, M., Hoefig, K., Merz, H., Feller, A.C., Kausch, I., Jocham, D., Warnecke, J.M. and Sczakiel, G. (2010) A Robust Methodology to Study Urine microRNA as Tumor Marker: microRNA-126 and microRNA-182 Are Related to Urinary Bladder Cancer. In: Urologic Oncology: Seminars and Original Investigations, Elsevier, Amsterdam, 655-661. https://doi.org/10.1016/j.urolonc.2009.01.027

[10] Michael, A., Bajracharya, S.D., Yuen, P.S., Zhou, H., Star, R.A., Illei, G.G. and Alevizos, I. (2010) Exosomes from Human Saliva as a Source of microRNA Biomarkers. Oral Diseases, 16, 34-38. https://doi.org/10.1111/j.1601-0825.2009.01604.x

[11] Park, N.J., Zhou, H., Elashoff, D., Henson, B.S., Kastratovic, D.A., Abemayor, E. and 
Wong, D.T. (2009) Salivary microRNA: Discovery, Characterization, and Clinical Utility for Oral Cancer Detection. Clinical Cancer Research, 15, 5473-5477. https://doi.org/10.1158/1078-0432.CCR-09-0736

[12] Xie, Y., Todd, N.W., Liu, Z., Zhan, M., Fang, H., Peng, H., Alattar, M., Deepak, J., Stass, S.A. and Jiang, F. (2010) Altered miRNA Expression in Sputum for Diagnosis of Non-Small Cell Lung Cancer. Lung Cancer, 67, 170-176. https://doi.org/10.1016/j.lungcan.2009.04.004

[13] Yu, L., Todd, N.W., Xing, L., Xie, Y., Zhang, H., Liu, Z., Fang, H., Zhang, J., Katz, R.L. and Jiang, F. (2010) Early Detection of Lung Adenocarcinoma in Sputum by a Panel of microRNA Markers. International Journal of Cancer, 127, 2870-2878. https://doi.org/10.1002/ijc.25289

[14] Schwarzenbach, H., Nishida, N., Calin, G.A. and Pantel, K. (2014) Clinical Relevance of Circulating Cell-Free microRNAs in Cancer. Nature Reviews Clinical Oncology, 11, 145. https://doi.org/10.1038/nrclinonc.2014.5

[15] Larrea, E., Sole, C., Manterola, L., Goicoechea, I., Armesto, M., Arestin, M., Caffarel, M.M., Araujo, A.M., Araiz, M. and Fernandez-Mercado, M. (2016) New Concepts in Cancer Biomarkers: Circulating miRNAs in Liquid Biopsies. International Journal of Molecular Sciences, 17, 627. https://doi.org/10.3390/ijms17050627

[16] Wang, K., Yuan, Y., Cho, J.-H., McClarty, S., Baxter, D. and Galas, D.J. (2012) Comparing the MicroRNA Spectrum between Serum and Plasma. PLoS ONE, 7, e41561. https://doi.org/10.1371/journal.pone.0041561

[17] Han, Y., Xu, G.-X., Lu, H., Yu, D.-H., Ren, Y., Wang, L., Huang, X.-H., Hou, W.-J., Wei, Z.-H. and Chen, Y.-P. (2015) Dysregulation of miRNA-21 and Their Potential as Biomarkers for the Diagnosis of Cervical Cancer. International Journal of Clinical and Experimental Pathology, 8, 7131.

[18] Wei, H., et al. (2017) Plasma miR-145 as a Novel Biomarker for the Diagnosis and Radiosensitivity Prediction of Human Cervical Cancer. Journal of International Medical Research, 45, 1054-1060. https://doi.org/10.1177/0300060517709614

[19] Ribeiro, J. and Sousa, H. (2014) MicroRNAs as Biomarkers of Cervical Cancer Development: A Literature Review on miR-125b and miR-34a. Molecular Biology Reports, 41, 1525-1531. https://doi.org/10.1007/s11033-013-2998-0

[20] Xie, H., Zhao, Y., Caramuta, S., Larsson, C. and Lui, W.-O. (2012) miR-205 Expression Promotes Cell Proliferation and Migration of Human Cervical Cancer Cells. Public Library of Science One, 7, e46990. https://doi.org/10.1371/journal.pone.0046990

[21] Zhang, J., Zheng, F., Yu, G., Yin, Y. and Lu, Q. (2013) miR-196a Targets Netrin 4 and regulates Cell Proliferation and Migration of Cervical Cancer Cells. Biochemical and Biophysical Research Communications, 440, 582-588. https://doi.org/10.1016/j.bbrc.2013.09.142

[22] Wen, F., Xu, J.-Z. and Wang, X.-R. (2017) Increased Expression of miR-15b Is Associated with Clinicopathological Features and Poor Prognosis in Cervical Carcinoma. Archives of Gynecology and Obstetrics, 295, 743-749. https://doi.org/10.1007/s00404-016-4286-4

[23] Li, B.H., Zhou, J.S., Ye, F., Cheng, X.D., Zhou, C.Y., Lu, W.G. and Xie, X. (2011) Reduced miR-100 Expression in Cervical Cancer and Precursors and Its Carcinogenic Effect through Targeting PLK1 Protein. European Journal of Cancer, 47, 2166-2174. https://doi.org/10.1016/j.ejca.2011.04.037

[24] Huang, Y., Li, Y., Wang, F.F., Lv, W., Xie, X. and Cheng, X. (2016) Over-Expressed miR-224 Promotes the Progression of Cervical Cancer via Targeting RASSF8. PLoS ONE, 11, e0162378. https://doi.org/10.1371/journal.pone.0162378 
[25] Villegas-Ruiz, V., Juárez-Méndez, S., Pérez-González, O.A., Arreola, H., Paniagua-García, L., Parra-Melquiadez, M., Peralta-Rodríguez, R., López-Romero, R., Monroy-García, A. and Mantilla-Morales, A. (2014) Heterogeneity of microRNAs Expression in Cervical Cancer Cells: Over-Expression of miR-196a. International Journal of Clinical and Experimental Pathology, 7, 1389.

[26] Gocze, K., Gombos, K., Kovacs, K., Juhasz, K., Gocze, P. and Kiss, I. (2015) MicroRNA Expressions in HPV-Induced Cervical Dysplasia and Cancer. Anticancer Research, 35, 523-530.

[27] Deftereos, G., Corrie, S.R., Feng, Q., Morihara, J., Stern, J., Hawes, S.E. and Kiviat, N.B. (2011) Expression of mir-21 and mir-143 in Cervical Specimens Ranging from Histologically Normal through to Invasive Cervical Cancer. PLoS ONE, 6, e28423. https://doi.org/10.1371/journal.pone.0028423

[28] Bumrungthai, S., Ekalaksananan, T., Evans, M.F., Chopjitt, P., Tangsiriwatthana, T., Patarapadungkit, N., Kleebkaow, P., Luanratanakorn, S., Kongyingyoes, B. and Worawichawong, S. (2015) Up-Regulation of miR-21 Is Associated with Cervicitis and Human Papillomavirus Infection in Cervical Tissues. PLOS ONE, 10, e0127109. https://doi.org/10.1371/journal.pone.0127109

[29] Zeng, K., Zheng, W., Mo, X., Liu, F., Li, M., Liu, Z., Zhang, W. and Hu, X. (2015) Dysregulated microRNAs Involved in the Progression of Cervical Neoplasm. Archives of Gynecology and Obstetrics, 292, 905-913. https://doi.org/10.1007/s00404-015-3702-5

[30] Zheng, W., Liu, Z., Zhang, W. and Hu, X. (2015) miR-31 Functions as an Oncogene in Cervical Cancer. Archives of Gynecology and Obstetrics, 292, 1083-1089. https://doi.org/10.1007/s00404-015-3713-2

[31] Bierkens, M., Krijgsman, O., Wilting, S.M., Bosch, L., Jaspers, A., Meijer, G.A., Meijer, C.J., Snijders, P.J., Ylstra, B. and Steenbergen, R.D. (2013) Focal Aberrations Indicate EYA2 and hsa-miR-375 as Oncogene and Tumor Suppressor in Cervical Carcinogenesis. Genes, Chromosomes and Cancer, 52, 56-68. https://doi.org/10.1002/gcc.22006

[32] Ma, L., Hong, Y., Lu, C., Chen, Y. and Ma, C. (2015) The Occurrence of Cervical Cancer in Uygur Women in Xinjiang Uygur Autonomous Region Is Correlated to microRNA-146a and Ethnic Factor. International Journal of Clinical and Experimental Pathology, 8, 9368.

[33] Lukic, A., Di Properzio, M., Carico, E., De Vitis, C., Giglio, S., Bordi, G., Caserta, D. and Mancini, R. (2018) MicroRNA-551b Expression Profile in Low and High-Grade Cervical Intraepithelial Neoplasia. European Review for Medical and Pharmacological Sciences, 22, 4448-4457.

[34] Yao, T. and Lin, Z. (2012) MiR-21 Is Involved in Cervical Squamous Cell Tumorigenesis and Regulates CCL20. Biochimica et Biophysica Acta (BBA)-Molecular Basis of Disease, 1822, 248-260. https://doi.org/10.1016/j.bbadis.2011.09.018

[35] Wang, X., Wang, H.-K., Li, Y., Hafner, M., Banerjee, N.S., Tang, S., Briskin, D., Meyers, C., Chow, L.T. and Xie, X. (2014) microRNAs Are Biomarkers of Oncogenic Human Papillomavirus Infections. Proceedings of the National Academy of Sciences, 111, 4262-4267. https://doi.org/10.1073/pnas.1401430111

[36] Cheung, T.-H., Man, K.-N.M., Yu, M.-Y., Yim, S.-F., Siu, N.S., Lo, K.W., Doran, G., Wong, R.R., Wang, V.W. and Smith, D.I. (2012) Dysregulated microRNAs in the Pathogenesis and Progression of Cervical Neoplasm. Cell Cycle, 11, 2876-2884. https://doi.org/10.4161/cc.21278

[37] Jiménez-Wences, H., Martínez-Carrillo, D.N., Peralta-Zaragoza, O., Campos-Viguri, G.E., Hernández-Sotelo, D., Jiménez-López, M.A., Muñoz-Camacho, J.G., Garzón-Bar- 
rientos, V.H., Illades-Aguiar, B. and Fernández-Tilapa, G. (2016) Methylation and Expression of miRNAs in Precancerous Lesions and Cervical Cancer with HPV16 Infection. Oncology Reports, 35, 2297-2305. https://doi.org/10.3892/or.2016.4583

[38] Shishodia, G., Shukla, S., Srivastava, Y., Masaldan, S., Mehta, S., Bhambhani, S., Sharma, S., Mehrotra, R., Das, B.C. and Bharti, A.C. (2015) Alterations in micrornas miR-21 and let-7a Correlate with Aberrant STAT3 Signaling and Downstream Effects during Cervical Carcinogenesis. Molecular Cancer, 14, 1-13. https://doi.org/10.1186/s12943-015-0385-2

[39] Chen, J., Yao, D., Li, Y., Chen, H., He, C., Ding, N., Lu, Y., Ou, T., Zhao, S. and Li, L. (2013) Serum microRNA Expression Levels Can Predict Lymph Node Metastasis in Patients with Early-Stage Cervical Squamous Cell Carcinoma. International Journal of Molecular Medicine, 32, 557-567. https://doi.org/10.3892/ijmm.2013.1424

[40] Ma, Q., Wan, G., Wang, S., Yang, W., Zhang, J. and Yao, X. (2014) Serum microRNA-205 as a Novel Biomarker for Cervical Cancer Patients. Cancer Cell International, 14, 81. https://doi.org/10.1186/s12935-014-0081-0

[41] Zhang, L., Chen, B. and Ding, D. (2017) Decreased microRNA-22 Is Associated with Poor Prognosis in Cervical Cancer. International Journal of Clinical and Experimental Pathology, 10, 9515.

[42] Leitao, M.C.G., Coimbra, E.C., Lima, R.C.P., Guimarães, M.L., Heráclio, S.A., Silva Neto, J.C. and de Freitas, A.C. (2014) Quantifying mRNA and microRNA with qPCR in Cervical Carcinogenesis: A Validation of Reference Genes to Ensure Accurate Data. PLoS ONE, 9, e111021. https://doi.org/10.1371/journal.pone.0111021

[43] Babion, I., Snoek, B.C., Novianti, P.W., Jaspers, A., van Trommel, N., Heideman, D.A., Meijer, C.J., Snijders, P.J., Steenbergen, R.D. and Wilting, S.M. (2018) Triage of High-Risk HPV-Positive Women in Population-Based Screening by miRNA Expression Analysis in Cervical Scrapes; a Feasibility Study. Clinical Epigenetics, 10, 1-10. https://doi.org/10.1186/s13148-018-0509-9

[44] Hou, T., Ou, J., Zhao, X., Huang, X., Huang, Y. and Zhang, Y. (2014) MicroRNA-196a Promotes Cervical Cancer Proliferation through the Regulation of FOXO1 and p27 Kip1. British Journal of Cancer, 110, 1260. https://doi.org/10.1038/bjc.2013.829

[45] Zhang, L., Zhan, X., Yan, D. and Wang, Z. (2016) Circulating microRNA-21 Is Involved in Lymph Node Metastasis in Cervical Cancer by Targeting RASA1. International Journal of Gynecological Cancer, 26, 810-816. https://doi.org/10.1097/IGC.0000000000000694

[46] Jiang, W., Pan, J.-J., Deng, Y.-H., Liang, M.-R. and Yao, L.-H. (2017) Down-Regulated Serum microRNA-101 Is Associated with Aggressive Progression and Poor Prognosis of Cervical Cancer. Journal of Gynecologic Oncology, 28, e75. https://doi.org/10.3802/jgo.2017.28.e75

[47] Xin, F., Liu, P. and Ma, C. (2016) A Circulating Serum miRNA Panel as Early Detection Biomarkers of Cervical Intraepithelial Neoplasia. European Review for Medical and Pharmacological Sciences, 20, 4846-4851.

[48] Ye, J., Cheng, X.-D., Cheng, B., Cheng, Y.-F., Chen, X.-J. and Lu, W.-G. (2019) MiRNA Detection in Cervical Exfoliated Cells for Missed High-Grade Lesions in Women with LSIL/CIN1 Diagnosis after Colposcopy-Guided Biopsy. BMC Cancer, 19, 1-9. https://doi.org/10.1186/s12885-019-5311-3

[49] Ribeiro, J., Marinho-Dias, J., Monteiro, P., Loureiro, J., Baldaque, I., Medeiros, R. and Sousa, H. (2015) miR-34a and miR-125b Expression in HPV Infection and Cervical Cancer Development. BioMed Research International, 2015, Article ID: 
304584. https://doi.org/10.1155/2015/304584

[50] Malta, M., Ribeiro, J., Monteiro, P., Loureiro, J., Medeiros, R. and Sousa, H. (2015) Let-7c Is a Candidate Biomarker for Cervical Intraepithelial Lesions: A Pilot Study. Molecular Diagnosis \& Therapy, 19, 191-196.

https://doi.org/10.1007/s40291-015-0145-4

[51] Kawai, S., Fujii, T., Kukimoto, I., Yamada, H., Yamamoto, N., Kuroda, M., Otani, S., Ichikawa, R., Nishio, E. and Torii, Y. (2018) Identification of miRNAs in Cervical Mucus as a Novel Diagnostic Marker for Cervical Neoplasia. Scientific Reports, 8, Article No. 7070. https://doi.org/10.1038/s41598-018-25310-1

[52] Shen, S.-N., Wang, L.-F., Jia, Y.-F., Hao, Y.-Q., Zhang, L. and Wang, H. (2013) Upregulation of microRNA-224 Is Associated with Aggressive Progression and Poor Prognosis in Human Cervical Cancer. Diagnostic Pathology, 8, 1-7. https://doi.org/10.1186/1746-1596-8-69

[53] Luo, M., Shen, D., Wang, W. and Xian, J. (2015) Aberrant Expression of microRNA-26b and Its Prognostic Potential in Human Cervical Cancer. International Journal of Clinical and Experimental Pathology, 8, 5542.

[54] Zhang, Y., Jia, L., Wang, P., Li, J., Tian, F., Chu, Z. and Kang, S. (2019) The Expression and Significance of lncRNA HOST2 and microRNA let-7b in HPV-Positive Cervical Cancer Tissues and Cell Lines. European Review for Medical and Pharmacological Sciences, 23, 2380-2390.

[55] Wang, Q.-X., Zhu, Y.-Q., Zhang, H. and Xiao, J. (2015) Altered MiRNA Expression in Gastric Cancer: A Systematic Review and Meta-Analysis. Cellular Physiology and Biochemistry, 35, 933-944. https://doi.org/10.1159/000369750

[56] Peiró-Chova, L., Peña-Chilet, M., López-Guerrero, J.A., García-Giménez, J.L., Alonso-Yuste, E., Burgues, O., Lluch, A., Ferrer-Lozano, J. and Ribas, G. (2013) High Stability of microRNAs in Tissue Samples of Compromised Quality. Virchows Archiv, 463, 765-774. https://doi.org/10.1007/s00428-013-1485-2

[57] Pritchard, C.C., Cheng, H.H. and Tewari, M. (2012) MicroRNA Profiling: Approaches and Considerations. Nature Reviews Genetics, 13, 358-369. https://doi.org/10.1038/nrg3198

[58] Vigneron, N., Meryet-Figuière, M., Guttin, A., Issartel, J.-P., Lambert, B., Briand, M., Louis, M.-H., Vernon, M., Lebailly, P. and Lecluse, Y. (2016) Towards a New Standardized Method for Circulating miRNAs Profiling in Clinical Studies: Interest of the Exogenous Normalization to Improve miRNA Signature Accuracy. Molecular Oncology, 10, 981-992. https://doi.org/10.1016/j.molonc.2016.03.005

[59] Monleau, M., Bonnel, S., Gostan, T., Blanchard, D., Courgnaud, V. and Lecellier, C.-H. (2014) Comparison of Different Extraction Techniques to Profile microRNAs from Human Sera and Peripheral Blood Mononuclear Cells. BMC Genomics, 15, Article No. 395. https://doi.org/10.1186/1471-2164-15-395

[60] Tan, G.W., Khoo, A.S.B. and Tan, L.P. (2015) Evaluation of Extraction Kits and RT-qPCR Systems Adapted to High-Throughput Platform for Circulating miRNAs. Scientific Reports, 5, Article No. 9430. https://doi.org/10.1038/srep09430

[61] Qiagen (2021) miScript II RT Kit.

https://www.qiagen.com/us/products/discovery-and-translational-research/pcr-qpc $\underline{\text { r-dpcr/qpcr-assays-and-instruments/mirna-qpcr-assay-and-panels/miscript-ii-rt-kit }}$

[62] Thermofisher Scientific (2021). https://www.thermofisher.com/order/catalog/product/AM1558\#/AM1558 